\title{
Strategi Dakwah Islam dalam Pengembangan Seni dan Peradaban
}

\author{
M. Wildan Yahya
}

ABSTRACT

As a distinctive feature of Islamic civilization, art become a way for communicating Islamic principles. The real essence of art is al-Tauhid which comes up from light chemical reactions. Al Tauhid has two aspects: the methodology and conceptual. The art of Islam itself has functions like these: reminder of tauhid, material transfiguration, structure transfiguration, and beauty.

Kata kunci: seni, Islam, Al-Tauhid

\section{Pendahuluan}

Dunia Islam sekalipun secara doktrinal memiliki sumber ajaran yang sama yaitu Al-Qur'an dan Al-Sunnah, tetapi secara kultural beraneka ragam. Di dalam masyarakat, terdapat bermacammacam peradaban (bentuk luar/material dari kebudayaan), yaitu: peradaban masyarakat pesisir, masyarakat agraris, masyarakat kota, masyarakat pedesaan, dsb.

Inti dari peradaban Islam adalah al-Tauhîd, sementara itu tauhid mempunyai dua segi atau dimensi: segi metodologis dan konseptual (alFaruqi, 1989:162). Metodologis menentukan bentuk penerapan dan implementasinya; konseptual menentukan warna (celupan) dan bingkainya. Dimensi metodologis meliputi tiga prinsip, yaitu: kesatuan, rasionalisme, dan toleransi. Dimensi isi meliputi lima prinsip, yaitu: metafisika, etika, aksiologi, masyarakat, dan estetika (al-Faruqi, 1989:112-126).
Spesifikasi yang akan menjadi sorotan kajian di dalam melihat warna Islam dalam peradaban adalah difokuskan pada seni. Seni dalam kehidupan manusia merupakan kebutuhan yang sangat mendasar dalam memenuhi tuntutan rasa dan spiritualitas. Dalam urusan yang sangat sederhana pun, seperti berjalan dan bertutur kata tetap memerlukan seni, agar tampak selalu indah dan menarik. Dalam makna yang lebih luas, seni tidak hanya dipandang sebagai suatu tata nilai yang bersifat abstrak, misalnya: indah atau tidak indah, menarik atau tidak menarik; akan tetapi juga keharmonisan dan keselarasan yang berdimensi luas, baik dimensi ekonomi, politik, maupun sosial budaya.

Menurut Quraish Shihab ${ }^{1}$, seni adalah keindahan. Ia merupakan ekspresi ruh dan budaya manusia yang mengandung dan mengungkapkan keselarasan, keserasian, keharmonisan dan ketepatan yang memesona batin manusia. Ia lahir dari sisi terdalam manusia berupa rasa dan imajinasi 
yang terekspresi lewat keterampilan bakat yang indah. Dorongan tersebut merupakan naluri manusia, atau fithrah yang dianugerahkan Allah kepada hamba-hamba-Nya.

Di bawah ini akan diutarakan beberapa sumbangan pemikiran dakwah Islam dalam pengembangan peradaban (seni).

\section{Dakwah Kultural}

Dakwah yang berarti ajakan, seruan, dan panggilan ke dalam cahaya Islam $^{2}$, selazimnya dikembangkan secara dinamis sesuai dengan tuntutan dan problema masyarakat. Tugas utama dakwah adalah menjauhkan manusia dari jalan yang bathil dan menyeru ke dalam jalan yang haq. Metode dakwah yang diajarkan Allah swt agar disampaikan secara arif bijaksana, nasehat yang baik, dan berdiskusi (berdebat) dengan santun. ${ }^{3}$ Tercapainya tujuan dakwah yang diharapkan juga berkaitan dengan pengembangan peradaban yang menampilkan pesan Islam di dalamnya.

Pengembangan peradaban terjadi karena pesan Islam sendiri yang kehadirannya menjadi "rahmat bagi alam semesta"4. Terdapat beberapa sebab munculnya warna-warni peradaban Islam, baik dikarenakan faktor internal maupun faktor eksternal. Salah satu faktor internal yang berpengaruh bagi tumbuh kembangnya keberagaman peradaban Islam adalah pesan alQur'an yang menyuruh umatnya berbuat al-'urf dan al-maslahah. ${ }^{5}$

Al-'urf adalah segala sesuatu yang sudah sangat dikenal karena telah menjadi kebiasaan atau tradisi yang shahîh (benar), baik yang menyangkut: perkataan, amal, atau dalam kaitannya dengan meninggalkan perbuatan tertentu, seringkali disebut sebagai adat. ${ }^{6}$ Adapun yang dimaksud dengan al-maslahah ${ }^{7}$ (al-mursalah) adalah kemaslahatan dan kebaikan yang tidak ditetapkan kebaikannya secara eksplisit oleh syari'ah, di samping tidak adanya hukum yang membenarkan atau menyalahkannya. Dalam kondisi yang sedemikian ini, maka seorang Mukmin memiliki keleluasaan untuk mengembangkan kebutuhannya yang pokok, yaitu: menjaga agama, menjaga diri, menjaga akal, menjaga keturunan, dan menjaga harta. ${ }^{8}$ Berkaitan dengan aspek sosial budaya maka berlaku prinsip ushûl: "Dasar bagi segala sesuatu (di dalam mu'amalah) adalah kebolehan".

Pada dasarnya, tidak ada batasan tertentu untuk mengembangkan aspek sosial peradaban, kecuali apabila benar-benar terdapat larangan untuk melakukannya. Dengan demikian, peradaban mendapat tempat yang sangat luas di dalam Islam untuk dikembangkan.

Adapun faktor eksternal yang berpengaruh bagi pengembangan peradaban Islam adalah faktorfaktor: geografis, demografis, sosial-religi pra Islam, watak, dan perbedaan-perbedaan penetrasi historis Islam. ${ }^{9}$

Kalau demikian, strategi dakwah kultural adalah suatu usaha untuk mengemas pesan-pesan Islam dalam budaya, bukan sekadar dari kepentingan-kepentingan formalistik, legalistik, dan eksklusif, akan tetapi lebih dari itu berusaha mencapai kepentingan-kepentingan yang lebih substantif, integratif, dan inklusif. ${ }^{10}$

Dalam rangka mendapatkan warna Islam yang terkemas pada peradaban, maka pemikiran tentang Islam dalam peradaban menjadi sangat penting untuk digali.

\section{Kimia Cahaya}

Ide untuk mengekspresikan spiritualitas seni Islam dalam peradaban, memiliki tiga cara penyaluran: geometri, yaitu mengungkapkan keindahan melalui sifat-sifat garis, sudut, bidang, dan ruang; irama, suatu gerakan atau susunan yang berturut-turut terjadi secara teratur, serasi, dan seimbang; dan cahaya, yang merupakan bentuk simbol kasat mata ketika bermaksud mengekspresikan keagungan Allah.

Tidak ada simbol yang lebih tepat bagi keagungan Tuhan dibandingkan cahaya. ${ }^{11}$ Untuk itu, para seniman Muslim berusaha untuk mengubah bahan dasar yang dipakainya ke dalam suatu vibrasi cahaya. Untuk tujuan inilah ia menutupi bagian dalam dari masjid atau istana, kadang-kadang juga bagian luarnya, dengan mosaik-mosaik dari ubin keramik. Untuk tujuan yang sama inilah para seniman mengubah bagian 
luar menjadi relief-relief berlubang untuk menyaring cahaya. Muqarnas, "stalaktit", juga dibuat untuk menjaring cahaya dan menyebarkannya dengan gradasi yang paling halus. ${ }^{12}$

Warna menunjukkan kekayaan interior dari cahaya. Cahaya yang dilihat secara langsung bisa merusak mata, melalui harmoni warnalah kita bisa meramalkan sifat yang sebenarnya, yang memuat fenomena visual dalam dirinya. Dalam tertib spiritual, kimia itu tidak lain adalah seni mengubah kesadaran jasmaniah kepada ruhaniah: "Jasmani harus dijadikan ruhani”, kata para ahli kimia, "karena ruhani harus menjadi jasmani". Secara analogi, kimia itu dalam konteks keberadaannya di sini, adalah mengubah batu menjadi cahaya, dan kemudian pada saatnya mengubah batu menjadi kristal. ${ }^{13}$

\section{Seni Ruang}

Kepedulian Islam kepada seni ruang tidak terlepas dari tujuan utamanya, yaitu menampilkan keindahan pada ruang yang terjalin dengan nilainilai tauhid. Karena itu, seni ruang dalam peradaban Islam akan meliputi empat subbagian penting kreasi artistik, yaitu: pertama, unit volume, bangunan besar tersendiri atau semi terpisah tanpa ruang interior, seperti: kolam, menara, jembatan, air mancur, dan terowongan air.

Kategori kedua, menambahkan ruang interior dan penutup pada dimensi horisontal dan vertikal, yang memberikan persepsi terhadap kedalaman, volume, dan massa.

Kategori ketiga, pertamanan, suatu bentuk seni yang dikembangkan secara ekstensif dan intensif oleh kaum Muslimin pada abad pertengahan. Ini mencakup ciri kreatif dan indah, baik dari sisi hortikultur ( penanaman dan perhatian terhadap aneka tanaman) maupun ciri aquakultur (ilmu tentang pemanfaatan artistik air di kanal, kolam, air terjun, dan mata air).

Komponen keempat, hubungan satu bangunan dengan bangunan terdekat secara berimbang memenuhi susunan yang harmonis. Hubungan dengan ruang terbuka di sekitarnya dan dengan halaman, kompleks, dusun, bagian kota, atau kota tempat bangunan itu berada pada posisi artistik dan fungsional. ${ }^{14}$

Adapun karakteristik inti dari seni ruang ${ }^{15}$ adalah:

(1) Abstraksi, penolakan umum terhadap figur atau kandungan ikonografis (antropomorfis), dan memodifikasi atau denaturalisasi secara imajinatif yang melahirkan keindahan dan tanda-tanda keagungan Tuhan (tauhid) melalui proses transfigurasi material dan struktural.

(2) Modul, menampilkan sejumlah unit atau modul internal yang dipadu secara aditif, seni ruang menghimpun entitas modular lebih kecil. Istana Islam bukanlah satu blok ruangan yang mengiring ke satu aula penting atau ruangan takhta. Istana Islam justru sering merupakan perpaduan unit-unit halaman, tiap unit terbuka ini bertindak sebagai pusat yang dikelilingi oleh ruangan-ruangan tambahan (penopang). Madrasah terdiri dari sejumlah segmen mandiri: untuk salat, sayap bangunan untuk administrasi, kelas, bagian asrama, tempat tinggal imam, dan juga penginapan untuk para musafir.

(3) Kombinasi suksesif, modul seni ruangan digabungkan untuk membentuk kombinasi lebih besar pada sejumlah tingkatan. Misal, ruangan terpisah untuk tempat tinggal, yang merupakan unsur modulat ruang paling dasar dan sederhana, digabungkan untuk membentuk ruang-ruang pembatas halaman terbuka. Pada tingkat kombinasi yang secara suksesif lebih ekspansif, sejumlah unit ruangan dan halaman menghasilkan tempat tinggal atau istana. ${ }^{16}$

(4) Repitisi, unit-unit yang merupakan komponen kombinasi suksesif ruang terbuka atau tertutup diulangi dalam bentuk identik atau beragam dalam struktur ruang aditif. Ini juga terjadi dalam unit internal bangunan individual dan taman, maupun dalam kombinasi bangunan yang membentuk kompleks pendidikan, ekonomi, domestik; bagian kota atau desa. Hal ini memberikan sumbangsih dalam tatanan simetris desain Islam, penafian terhadap partikularisme bagian-bagiannya, dan kualitas 
aditif arabesque ruang.

(5) Dinamisme, pemahaman dan apresiasi seni ruang Islam harus dilakukan dengan menjelajahi unit-unit ruangnya. Kesan atau pemandangan total tak mungkin diperoleh dari kejauhan. Tak ada perkembangan atau evolusi arsitektural ke satu titik klimaks estetis. Bangunan individual begitu terjalin dengan sekitarnya, sehingga sulit mengetahui di mana bangunan tersebut berakhir dan di mana struktur di sebelahnya berasal. Bahkan, dinding kota tidak tampak dan hanya terwujud lewat pintu gerbang. Dinding kota ini sepenuhnya berurat-berakar dalam struktur kota, yang tersusun dari dinding rumah-rumah pribadi yang terletak pada perbatasan wilayah ruang yang berhubungan. Karena itu, contoh seni ruang Islam haruslah dialami secara dinamis, bukan dalam momen waktu tunggal yang statis. ${ }^{17}$

(6) Kerumitan, yaitu dekorasi dua atau tiga dimensi yang merupakan kombinasi unit ruang yang membentuk unit isi, bangunan, taman, atau lingkungan Islami. Gambaran dari desain yang dilapis, dipahat, atau dilukis; yang juga merupakan organisasi kompleks struktur dan unsur-unsur artistik yang diperkuat oleh dekorasi interior dan eksterior. Modul pada tiap tingkat kombinasi di dalam lingkungan yang terbangun memberikan bagian otonom yang menjamin privasi dan keterpisahan internal, namun pemisahan itu tidak dilakukan melalui isolasi eksternal antarstruktur. Sebaliknya, bangunan berdekatan di kota Islam tradisional membentuk kumpulan rumit dan berdempetan, yang disela oleh ruang terbuka bagi masuknya udara dan sinar mata hari. Ruang terbuka itu merupakan halaman-dalam. Hanya jalan utama untuk melintas yang sangat terlihat. Jalan untuk pejalan kaki merupakan jalan semiprivat, atau jalan beratap yang memberikan akses dari sektor publik ke ruang pribadi.

\section{5. "Arabesque"}

Arabesque $^{18}$ adalah suatu jenis keindahan yang dialektis, yang di dalamnya logika bergabung dengan ritme yang hidup terus-menerus. Ia memiliki dua unsur dasar: saling berjalin dan motif tanaman. Yang pertama, sebenarnya berasal dari spekulasi geometris; dan yang kedua, merepresentasikan satu jenis formulasi grafis irama, yang diekspresikan dalam desain spiral, yang mungkin tidak banyak diambil dari bentuk tanaman, tetapi dari suatu simbolisme yang murni linear.

Setelah Hellenisme, yang pada dasarnya merupakan seni antropomorfis (ikonoklasme) mengalami kemunduran, Islam tampil dengan seni arabesque yang pada prinsipnya menentang bentuk seni antropomorfis. Islam kemudian mengasimilasikan unsur-unsur arkaik dan mereduksinya ke dalam formulasi-formulasi yang paling abstrak dan paling umum. Islam memberinya pemahaman tertentu sehingga melenyapkan kualitas-kualitas magis yang mungkin dimiliki. Islam memberinya kejernihan intelektual dengan suatu keindahan spiritual.

\section{Ornamentasi dalam Seni Islam}

Ornamen adalah hiasan dalam arsitektur berupa kerajinan tangan, lukisan, pahatan, dekorasi, dsb. Dalam seni Islam, ornamentasi bukanlah sekadar hiasan kosong tanpa arti untuk mengisi lapisan karya atau ruang yang kasat mata. Akan tetapi memiliki fungsi-fungsi sebagai berikut: pengingat tauhid, transfigurasi material, transfigurasi struktur, dan keindahan. ${ }^{19}$

Pengingat Tauhid, pola indah yang ditemukan dalam seni Islam berorientasi untuk mengingat dan menginternalisasikan kehadiran Allah di dalam diri. Transendensi Tuhan yang dilekatkan di dalam kerajinan tangan, lukisan, pahatan dan dekorasi memberi arti bagi keagungan-Nya. Dengan demikian, ornamentasi justru merupakan inti dari peningkatan spiritualisasi kreasi artistik Islam.

Transfigurasimaterial, ${ }^{20}$ adalah sebagai seni yang menekankan abstraksi atau denaturalisasi dalam memilih dan memakai materi subjek. Alasannya: pertama, karena istilah ini menyiratkan makna bahwa objek yang ditransfigurisasikan oleh ornamentasi mengalami perubahan bentuk atau tampilan, namun bukan perubahan substansi. Kedua, istilah "transfigurasi" menyiratkan bahwa 
perubahannya bukan semata-mata perubahan, namun perubahan yang membawa kemuliaan ruhani atau spiritualisasi. ${ }^{21}$

Transfigurasi struktur, seni Islam berusaha menyamarkan kerangka dasar, sementara di banyak tradisi seni dunia berupaya menekankan struktur dasar karya tertentu. Inilah ciri lain produk seni yang dirancang untuk menjauhkan perhatian dari karakter dan unsur duniawi menuju tatanan ungkapan dan makna yang lebih tinggi.

Keindahan, fungsi keempat ornamen adalah memperindah dan menghias. Fakta ini berdasar pada simetrisnya, pada warnanya yang menyenangkan dan bentuknya yang beragam dan indah. Selanjutnya memberikan dimensi tambahan dari keindahan untuk Muslim yang melihatnya; karena figur atau objek, frase atau gerakan, bait atau lukisan yang mengungkapkan tauhid. ${ }^{22}$

\section{Kaligrafi}

Dalam seni artefak dan naskah-naskah klasik, huruf-huruf Arab berkombinasi secara halus dengan model arabeque, khususnya dengan motif tanaman, yang dengan demikian memiliki hubungan lebih dekat dengan simbolisme Asiatik tentang pohon dunia; dedaunan dari pohon ini disesuaikan dengan kata-kata yang diambil dari kitab suci. $^{23}$

Kaligrafi Arab sendiri memiliki kemungkinankemungkinan dekoratif yang sangat kaya dan tiada habisnya. Bentuk-bentuk dasarnya beragam antara tulisan kufi yang monumental, dengan bentuk garis lurus dan sela vertikal, dan naskhi dengan garis seperti air dan meliuk-liuk. Kekayaan tulisan Arab berasal dari fakta bahwa ia telah mengembangkan dua dimensi: vertikal, memberikan huruf-huruf itu bermartabat yang analog dengan "lengkungan" tenun kain, sesuai dengan esensi segala sesuatu yang permanen. Horizontal, menghubungkannya dengan satu aliran yang terus-menerus, analog dengan "tenunan" yang mengekspresikan kejadian atau materi yang menghubungkan sesuatu dengan yang lain. Arti penting dari kaligrafi, di dalamnya coretan vertikal mentransendensikan dan mengatur aliran lekak-lekuk dari goresan-goresan yang lain. ${ }^{24}$

\section{Penutup}

Usaha untuk mengembangkan peradaban Islam yang berpusat pada tauhid merupakan amal sholeh dalam mendakwahkan Islam secara kultural. Dakwah yang sedemikian ini disebut sebagai dakwah bilhal, yaitu dakwah melalui karya dan perbuatan untuk mengajak manusia kepada kebenaran Ilahi.

Tentu saja, sesuai dengan perkembangan iptek yang sangat pesat, maka warna Islam yang terdapat dalam peradaban secara dinamis akan terus berkembang. Ijtihad kultural juga perlu terus dikembangkan dalam rangka menjadikan Islam rahmatan lil'alamin. Wallahu a'lam bishawwab.

\section{Catatan Akhir}

1 Lihat Quraisy Shihab, Wawasan Islam, Mizan, Bandung, h. 383 .

2 Lihat Jum'ah Amin Abdul Aziz, Ad-Dakwah, Qawa'id wa Ushul, Dar al-Dakwah, Iskandaria, Mesir, 1997, h. 26.

3 Lihat Q.S. al-Nahl/16: 125.

4 Lihat Q.S. Al-Anbiya“/21: 108.

5 Lihat QS. Al-A'raf / 7: 199 \& QS. Yunus / 10 : 57.

6 Abu Wahab Khalaf, 'Ilm Ushul al-Fiqh, Dakwah Islamiyah Sabab Azhar, 149.

Ibid. h.141.

8 Muhammad Abu Zahrah, Ushul al-Fiqh, Dar al-Fikr al'Arabi, h. 278.

9 Lihat J. Spencer Trimingham, The Sufi Orders in Islam, Oxford University Press, London, 1973, h. 227.

10 Bahtiar Effendy, Islam dan Negara, Transformasi Pemikiran dan Praktik Politik Islam di Indonesia, Paramadina, 1998, h.58.

11 Lihat QS. Al-Nur/24: 35).

12 Sayyed Hossein Nasr, Islamic Spirituality: "Manifestations", h. 660 .

13 Ibid., h. 660 .

14 Ibid., h. 442.

15 Lihat 
16 ibid Ismail Razi al-Faruqi, The Cultural, h. 165-167.

17 Ibid.

18 Sayyed Hossein Nasr, Islamic Spirituality: "Manifestations", h. 660 .

19 Ismail R. al-Faruqi, The Culture, h. 411-417.

21 Ibid., h. 412.

22 Ibid., h. 416

23 Sayyed Hosein Nasr, Islamic Spirituality, h. 656.

24 Ibid., h. 657-658.

\section{Daftar Pustaka}

Al-Qur'an al-Karim.

Antoniou, Jim. 1981. Islamic Cities and Conservation. Paris: Unesco.
Effendy, Bahtiar. 1998. Islam dan Negara, Transformasi Pemikiran dan Praktik Politik Islam di Indonesia. Jakarta: Paramadina.

Faruqi, Ismail R. al-. 1986. The Cultural Atlas of Islam. New York: Macmillan Publishing Company.

Khalaf, Abdul Wahab. 1968. 'Ilm Ushul al-Fiqh. Mesir: Dakwah Islamiyah Syabab al-Azhar.

Nasr, Sayyed Hossein. 1991. Islamic Spirituality: Manifestations. The Crossroad Publishing Company.

Thalu, Muhyiddin. 1982. al-Funun al-Zukhrafiyah. Dar Damsyiq.

Zahrah, Muhammad Abu. tt. Ushul al-Fiqh. Libanon: Darul Fikri al-'Arabi. 